\title{
Routine intraoperative frozen section adds little value to the management of thyroid nodules with Bethesda III cytology
}

\section{Dear Editor,}

We would like to highlight the need to reduce intraoperative frozen section (FS) during diagnostic hemithyroidectomy performed on thyroid nodules with Bethesda III cytology. Thyroid nodules are increasingly diagnosed and subjected to fine needle aspiration cytology. Bethesda III is a cytological category that consists of atypia or follicular lesion of undetermined significance, and carries a $6-30 \%$ risk of malignancy. ${ }^{1}$ Hemithyroidectomy is commonly performed on Bethesda III nodules to obtain a definitive histological diagnosis. FS during hemithyroidectomy allows some thyroid cancers-predominantly papillary thyroid carcinoma (PTC) - to be diagnosed intraoperatively. ${ }^{2}$ Such a diagnosis may prompt the surgeon to perform a total thyroidectomy and/or central neck dissection. However, the routine use of FS on Bethesda III nodules is controversial considering the low probability of a diagnosis of malignancy on $\mathrm{FS},{ }^{2}$ and such a diagnosis would not necessarily alter the extent of surgery. ${ }^{3}$ Until 2016, we practised FS routinely on Bethesda III nodules followed by total thyroidectomy with or without elective central neck dissection, if thyroid carcinoma was diagnosed on FS-except for papillary thyroid microcarcinomas. In view of recent guidelines recommending hemithyroidectomy without elective central neck dissection to be an acceptable treatment of well-differentiated intrathyroidal papillary carcinomas that are $\leq 4 \mathrm{~cm},{ }^{3}$ we reviewed our experience to determine how FS in Bethesda III nodules may be reduced.

After obtaining ethics approval from our institution in Singapore, we studied the preoperative clinical, sonographic and pathologic characteristics associated with the diagnosis of malignancy or suspicion of malignancy on FS in 98 Bethesda III nodules from 98 patients. These patients underwent hemithyroidectomy and FS in our department from 2010 to 2016. Sonographic characteristics were retrieved from the radiologist's report and suspicion of malignancy, defined by the presence of any of these featuresmicrocalcification, marked hypoechogenicity, tallerthan-wider configuration, irregular margin, extrathyroidal extension or abnormal cervical lymph nodes-was considered present if it was so specified by the radiologist. Cytologic nuclear atypia was diagnosed when nuclear enlargement, pale or clear chromatin, grooves or pseudoinclusions were seen in various combinations in the follicular cells, but were insufficient for a diagnosis of suspicion of malignancy (Bethesda V) or malignancy (Bethesda VI).

The age of the patients ranged from 16.6-79.7 years (mean 51.7 years). Seventy-two were female $(73.5 \%)$. On FS, only 4 nodules $(4.1 \%)$ were diagnosed as malignant ( 3 papillary and 1 medullary carcinoma), and 4 were suspicious of malignancy ( 2 papillary and 2 follicular carcinoma). The rest $(91.8 \%)$ were benign or indeterminate of malignancy. On univariate analysis, the preoperative characteristics associated with a diagnosis of malignancy or suspicion of malignancy on FS were nuclear atypia $(P=0.009)$, microcalcification $(P=0.003)$ and the radiologist's suspicion of malignancy on sonography $(P=0.001)$. On multivariate logistic regression, only microcalcification $(P=0.029)$ and radiologist's suspicion of malignancy on sonography $(P=0.030)$ remained significant (Table 1$)$. This is consistent with the understanding that sonographic suspicion is most frequently associated with papillary thyroid carcinoma. ${ }^{4}$

However, even if we only selected Bethesda III nodules with either microcalcification or a radiologist's suspicion of malignancy for FS, the likelihood of a diagnosis of malignancy on FS would only increase from:

$$
\frac{4}{98}=4.1 \% \quad \rightarrow \quad \frac{2}{23}=8.7 \%
$$

Moreover, the size of the 3 PTCs diagnosed on FS were $1.3 \mathrm{~cm}, 2.6 \mathrm{~cm}$ and $3.5 \mathrm{~cm}$ pathologically. None demonstrated gross extrathyroidal extension or nodal metastasis intraoperatively. Only 1 tumour diagnosed as malignant on FS, a medullary carcinoma (MTC), showed gross extrathyroidal extension and gross nodal metastases. This would be the only tumour that certainly required a total thyroidectomy and neck dissection. Therefore, FS in our series of Bethesda III nodules would convincingly change the extent of surgery in only 1 out of 98 patients $(1.02 \%)$. Even in this patient, the fact that his MTC was diagnosed as Bethesda III was unusual. Upon review of the cytology, we found clues of MTC - the most important being the presence of singly dispersed cells misinterpreted as follicular cells. However, the cytology lacked amyloid, and was insufficient for immunohistochemistry. Neither was serum calcitonin or carcinoembryonic antigen available because MTC was not suspected clinically. If it had been, this MTC would probably be diagnosed 
Table 1. Factors predictive of malignancy or suspicion of malignancy on frozen section in thyroid nodules with Bethesda III cytology

\begin{tabular}{|c|c|c|c|c|c|}
\hline $\begin{array}{ll}\text { Preoperative } & \begin{array}{l}\text { Frozen } \\
\text { section } \\
\text { characteristics }\end{array}\end{array}$ & $\begin{array}{c}\text { Benign or } \\
\text { indeterminate } \\
\mathbf{n}=90\end{array}$ & $\begin{array}{c}\text { Suspicious or } \\
\text { malignant } \\
n=8\end{array}$ & $\begin{array}{c}\text { Univariate } \\
P \text { value }\end{array}$ & $\begin{array}{l}\text { Multivariate } \\
\text { odds ratio } \\
(95 \% \text { CI) }\end{array}$ & $\begin{array}{c}\text { Multivariate } \\
P \text { value }\end{array}$ \\
\hline Male, no. $(\%)$ & $22(24.4)$ & $4(50.0)$ & 0.203 & $\begin{array}{c}4.43 \\
(0.69-28.65)\end{array}$ & 0.118 \\
\hline $\begin{array}{l}\text { Hoarseness, no. (\%) } \\
\text { Yes } \\
\text { No } \\
\text { Unknown }\end{array}$ & $\begin{array}{c}1(1.1) \\
87(98.9) \\
2\end{array}$ & $\begin{array}{c}1(12.5) \\
7(87.5) \\
0\end{array}$ & 0.161 & & \\
\hline $\begin{array}{l}\text { Dysphagia, no. (\%) } \\
\text { Yes } \\
\text { No } \\
\text { Unknown }\end{array}$ & $\begin{array}{c}6(6.8) \\
82(93.2) \\
2\end{array}$ & $\begin{array}{c}1(12.5) \\
7(87.5) \\
0\end{array}$ & 0.467 & & \\
\hline $\begin{array}{l}\text { Subjective growth, no. }(\%)^{\mathrm{a}} \\
\text { Yes } \\
\text { No } \\
\text { Unknown }\end{array}$ & $\begin{array}{c}7(8.0) \\
81(92.0) \\
2\end{array}$ & $\begin{array}{c}1(12.5) \\
7(87.5) \\
0\end{array}$ & 0.515 & & \\
\hline $\begin{array}{l}\text { Vocal cord palsy, no. (\%) } \\
\text { Yes } \\
\text { No } \\
\text { Unknown }\end{array}$ & $\begin{array}{c}1(1.1) \\
87(98.9) \\
2\end{array}$ & $\begin{array}{c}0 \\
8(100) \\
0\end{array}$ & 1.000 & & \\
\hline Median ${ }^{\mathrm{b}}$ size in $\mathrm{mm}^{\mathrm{c}}$ (range) & $\begin{array}{c}26.5 \\
(1.0-75.0)\end{array}$ & $\begin{array}{c}36.0 \\
(13.0-76.0)\end{array}$ & 0.237 & & \\
\hline $\begin{array}{l}\text { Echogenicity, no. }(\%)^{\mathrm{c}} \\
\text { Hypoechoic } \\
\text { Isoechoic } \\
\text { Neither } \\
\text { Unknown }\end{array}$ & $\begin{array}{c}38(52.8) \\
12(16.7) \\
22(30.6) \\
18\end{array}$ & $\begin{array}{c}5(100) \\
0 \\
0 \\
3\end{array}$ & 0.215 & & \\
\hline $\begin{array}{l}\text { Consistency, no. }(\%)^{c} \\
\text { Solid } \\
\text { Solid-cystic } \\
\text { Neither } \\
\text { Unknown }\end{array}$ & $\begin{array}{c}45(50.6) \\
44(49.4) \\
0 \\
1\end{array}$ & $\begin{array}{c}5(62.5) \\
3(37.5) \\
0 \\
0\end{array}$ & 0.716 & & \\
\hline Internal vascularity, no. $(\%)^{\mathrm{c}}$ & $29(32.2)$ & $5(62.5)$ & 0.121 & & \\
\hline Taller-than-wider, no. $(\%)^{\mathrm{c}}$ & $1(1.1)$ & 0 & 1.00 & & \\
\hline Ill-defined margins, no. $(\%)^{\mathrm{c}}$ & $5(5.6)$ & $1(12.5)$ & 0.409 & & \\
\hline Microcalcification, no. $(\%)^{c}$ & $11(12.2)$ & $5(62.5)$ & 0.003 & $\begin{array}{c}8.56 \\
(1.25-58.51)\end{array}$ & 0.029 \\
\hline $\begin{array}{l}\text { Suspicion of malignancy on } \\
\text { sonography, no. }(\%)^{\mathrm{d}}\end{array}$ & $9(10.0)$ & $5(62.5)$ & 0.001 & $\begin{array}{c}7.82 \\
(1.25-58.51)\end{array}$ & 0.030 \\
\hline $\begin{array}{l}\text { Nuclear atypia, no. (\%) } \\
\text { Yes } \\
\text { No } \\
\text { Unknown }\end{array}$ & $\begin{array}{c}42(46.7) \\
42(46.7) \\
6(6.7)\end{array}$ & $\begin{array}{c}6(75.0) \\
0 \\
2(25.0)\end{array}$ & 0.009 & $\begin{array}{c}0.60 \\
(0.15-2.40)\end{array}$ & 0.469 \\
\hline
\end{tabular}

CI: confidence interval; NA: not applicable

a Patient-reported growth in the thyroid nodule

${ }^{\mathrm{b}}$ Size was not parametrically distributed

c Sonographic features

'Based on the radiologist's report

NA: These characteristics were not incorporated into the multivariate analysis because they were not significant on univariate analysis, but age and sex were included because they are traditional predictors of thyroid malignancy. 
preoperatively, therefore not requiring FS for confirmation of malignancy.

Up till 2015, professional bodies such as the American Thyroid Association (ATA) have endorsed total thyroidectomy as a preferred treatment for PTCs $>1 \mathrm{~cm}$ in the longest dimension, and permitted elective central neck dissection for these PTCs. ${ }^{5}$ Referenced by ATA, a study of the US National Cancer Database (NCDB) demonstrated that total thyroidectomy was associated with lower hazard of recurrence or death in patients with PTCs $>1 \mathrm{~cm} .{ }^{6}$ However, single institution studies with more details on patient selection ${ }^{7}$ and a contemporary analysis of the $\mathrm{NCDB}^{8}$ have since demonstrated no detriment to disease-specific or recurrence-free survival in patients who were treated with hemithyroidectomy alone for well-differentiated intrathyroidal PTCs $\leq 4 \mathrm{~cm}$ without nodal metastasis clinically. Therefore, both hemithyroidectomy and total thyroidectomy are now endorsed by ATA as management options for these PTCs in the absence of a history of neck irradiation or familial PTC. ${ }^{3}$

Recent guidelines worldwide, including a consensus statement from Singapore, ${ }^{9}$ are also supporting this "less may be more" approach towards the treatment of these typically indolent cancers, as hemithyroidectomy decreases the need for thyroid hormone replacement, calcium supplementation and the risk of recurrent laryngeal nerve injury. As elective central neck dissection has not been shown to improve disease-specific survival in patients with these PTCs, ${ }^{10}$ but instead increases the risk of hypoparathyroidism and recurrent laryngeal nerve injury, the ATA made a strong recommendation against it since 2015. Therefore, current guidelines recommend that only PTCs $>4 \mathrm{~cm}$, or those with gross extrathyroidal extension or gross nodal/distant metastases, be routinely treated with total thyroidectomy and central neck dissection. ${ }^{3,9}$ Although sonographic suspicion of malignancy increases the likelihood of diagnosing thyroid cancer on FS, the extent of surgery would not necessarily change considering recent evidence. Selecting Bethesda III nodules that are sonographically suspicious and $>4 \mathrm{~cm}$, or those with gross extrathyroidal extension or metastasis for FS, may be a way to improve the utility of this investigation.

\section{Declaration}

This paper was first presented as oral presentations at the ENT World Congress, 2017 and the Asia Pacific Thyroid Congress, 2018. The authors have no funding and conflict of interest to declare. collection, and Dr Aruni Seneviratna, a clinical epidemiologist at Tan Tock Seng Hospital, for advice on the statistical analyses performed in this study.

\section{REFERENCES}

1. Cibas ES, Ali SZ. The 2017 Bethesda System for Reporting Thyroid Cytopathology. Thyroid 2017;27:1341-6.

2. Guevara N, Lassalle S, Benaim G, et al. Role of frozen section analysis in nodular thyroid pathology. Eur Ann Otorhinolaryngol Head Neck Dis 2015;132:67-70.

3. Haugen BR, Alexander EK, Bible KC, et al. 2015 American Thyroid Association Management Guidelines for Adult Patients with Thyroid Nodules and Differentiated Thyroid Cancer: The American Thyroid Association Guidelines Task Force on Thyroid Nodules and Differentiated Thyroid Cancer. Thyroid 2016;26:1-133.

4. Remonti LR, Kramer CK, Leitão CB, et al. Thyroid ultrasound features and risk of carcinoma: a systematic review and metaanalysis of observational studies. Thyroid 2015;25:538-50.

5. American Thyroid Association (ATA) Guidelines Taskforce on Thyroid Nodules and Differentiated Thyroid Cancer, Cooper DS, Doherty GM, et al. Revised American Thyroid Association management guidelines for patients with thyroid nodules and differentiated thyroid cancer. Thyroid 2009;19:1167-214. Erratum in: Thyroid 2010;20:674-5.

6. Bilimoria KY, Bentrem DJ, Ko CY, et al. Extent of surgery affects survival for papillary thyroid cancer. Ann Surg 2007;246: 375-81; discussion 381-4.

7. Nixon IJ, Ganly I, Patel SG, et al. Thyroid lobectomy for treatment of well differentiated intrathyroid malignancy. Surgery 2012; 151:571-9.

8. Adam MA, Pura J, Gu L, et al. Extent of surgery for papillary thyroid cancer is not associated with survival: an analysis of 61,775 patients. Ann Surg 2014;260:601-5; discussion 605-7.

9. Organizing Committee for the 1st Singapore Differentiated Thyroid Cancer Consensus Meeting. Multidisciplinary care for well-differentiated thyroid cancer. Singapore Consensus - August 2016. Available at: http://emss.org.sg/wp-content/uploads/2017/10/ Thyroid-Cancer-Consensus-SG-Quick-Reference-Guide.pdf. Accessed on 24 August 2021.

10. Viola D, Materazzi G, Valerio L, et al. Prophylactic central compartment lymph node dissection in papillary thyroid carcinoma: clinical implications derived from the first prospective randomized controlled single institution study. J Clin Endocrinol Metab 2015;100:1316-24.

Hao $\underline{\operatorname{Li}}{ }^{1} M C I$, Julian Park Nam $\underline{\text { Goh }}{ }^{2} F R C R$,

Karandikar Amit Anand ${ }^{2}{ }_{F R C R}$,

Manish Mahadeorao Bundele ${ }^{3}$ FRCPath,

Ernest Wei Zhong $\underline{\mathrm{Fu}}^{1}$ FAMS(ENT),

Jereme Yijin Gan ${ }^{1}$ FAMS(ENT),

Ming Yann $\underline{\operatorname{Lim}}{ }^{1}{ }_{R R C S(E N T)}$, Mandy $\underline{\operatorname{Mak}}{ }^{1} M B B S$

${ }^{1}$ Department of Otorhinolaryngology, Tan Tock Seng Hospital, Singapore

${ }^{2}$ Department of Diagnostic Radiology, Tan Tock Seng Hospital, Singapore

${ }^{3}$ Department of Pathology, Tan Tock Seng Hospital, Singapore

\section{Acknowledgements}

We would like to thank Sister Sow Fong Lee, the chief nurse of the Operating Theatre of Tan Tock Seng Hospital, for facilitating the data
Correspondence: Dr Hao Li, Department of Otorhinolaryngology, Tan Tock Seng Hospital, 11 Jalan Tan Tock Seng, Singapore 308433.

Email:1i_hao@ttsh.com.sg 